\title{
Integrated Rehabilitation for Children with Cerebral palsy: A Prospective Observational Study
}

\author{
Hye-Yoon Lee ${ }^{1}$, Young-Ju Yun ${ }^{2 *}$, Yong-Beom $\mathrm{Shin}^{3}$, Soo-Yeon Kim ${ }^{4}$, Jun-hee Han ${ }^{5}$, Sun-ae Yu ${ }^{6}$ \\ ${ }^{1}$ School of Korean medicine, Pusan National University \\ ${ }^{2}$ Department of Integrative Medicine, School of Korean Medicine, Pusan National University \\ ${ }^{3}$ Department of Rehabilitation Medicine, Pusan National University School of Medicine and Biomedical Research Institute, \\ Pusan National University Hospital \\ ${ }^{4}$ Department of Rehabilitation Medicine, Pusan National University School of Medicine, Research Institute of Convergence \\ for Biomedical Science and Technology, Pusan National University Yangsan Hospital \\ ${ }^{5}$ Department of Statistics \& Institute of Statistics, Hallym University \\ ${ }^{6}$ Department of Pediatrics, College of Oriental Medicine, Dong-Eui University
}

\begin{abstract}
Objectives: This study aimed to analyse: 1) the clinical effectiveness and safety of traditional Korean Medicine (TKM) and frequency of TKM therapies used and their relationship with conventional treatments.

Methods: This prospective observational study enrolled children with cerebral palsy (CP) aged 6-78 months ( $\mathrm{n}=126)$. The children who used herbal medication for $>30$ days or acupuncture treatment $>12$ sessions within 6 months were defined as the integrated rehabilitation (IR) group; the remaining participants were included in the conventional rehabilitation (CR) group.

Results: Changes in the Gross Motor Function Measure-66 (GMFM-66) were greater in the IR group (6.4 \pm 6.1$)$ than in the CR group (4.6 \pm 5.8$)$. The reduction in the number of other health problems was greater in the IR group than in the CR group. The GMFM-66 improvement was greatest in gross motor function classification system level 1. There was no between-group difference in the frequency of rehabilitation therapy $(10.9 \pm 6.6$ and $12.0 \pm 9.9$ in the IR and CR groups, respectively).

Conclusion: TKM may offer additional benefits in terms of the GMFM-66 score and other health problems. However, there is a need for further randomized controlled trials involving a restricted CP type and a controlled treatment type and intensity to confirm these findings.
\end{abstract}

$\overline{K e y}$ Words $:$ acupuncture, cerebral palsy, herbal medicine, integrated rehabilitation, pediatric rehabilitation

\section{Introduction}

Cerebral palsy (CP) refers to a collection of motor disorders caused by brain damage that occurs before, during, or after birth. ${ }^{1)}$ Complementary and alternative medicine has been globally used for treating $\mathrm{CP}^{2-5)}$ In South Korea, traditional
Korean medicine (TKM) is widely used concomitantly with conventional rehabilitation therapy (RT), ${ }^{6}$ and there is up to a $40 \%$ rate of TKM use among children with $\mathrm{CP}^{7)}$

For the treatment of $\mathrm{CP}$ of children, a multidisciplinary approach is required and various treatment methods are used since various

\footnotetext{
- Received: 6 June 2021

- Revised : 31 July 2021

- Accepted : 5 Novermber 2021

- Correspondence to : Young-Ju Yun

20 Geumo-ro, Yangsan-si, Gyeongsangnam-do, Republic of Korea

Tel : +82-55-360-5955, Fax : +82-55-360-5906, Email : mdkmdyun@pusan.ac.kr
} 
symptoms occur depending on the lesion site. Standard treatments for CP include interventions to regulate muscle tone and to prevent joint contractures such as physical therapy (PT), neurophysiological therapies (Bobas, a method that supresses abnormal movement patterns and normalizes muscle tension; Vojta, which repeatedly stimulates specific parts of the body to induce movement and establishes normal movement patterns in brain), muscle relaxants, nerve block or botulinum toxin injections, assistant devices, and orthopaedic or neurosurgical surgery. Occupational therapy (OT), a training to perform activities in daily life, speech therapy (ST), or swallowing training can be used according to symptoms ${ }^{8,9)}$.

Previous systematic reviews on acupuncture for children with $\mathrm{CP}$ have revealed that combining acupuncture and conventional treatment is more effective than conventional treatment alone. ${ }^{10,11)}$ Another study reported that herbal medicine or Tuina combined with conventional treatment is beneficial for children with $\mathrm{CP} .{ }^{12)}$ The efficacy of TKM for CP currently remains unclear. The added effect on combining TKM with conventional treatment should be investigated since the latter is currently administered as an adjuvant with conventional treatment. ${ }^{13)}$

This prospective, observational, and cross-sectional study examined factors affecting TKM use via survey administration following recruitment. ${ }^{13)}$ Patients with non-spastic-type CP or other health problems tended to be high-frequency users of TKM. These results suggest that atypical patients, or patients with difficult-to-treat conditions, tend to seek TKM.

Herein we report the results of this study and examine the forms of TKM used, with a focus on the type of TKM, frequency of use, and the effectiveness of TKM on CP symptoms.

\section{Methods}

\section{Study design and setting}

We conducted a one-year, multi-center, prospective, observational study. This comparative observational study included a CR group and an integrated rehabilitation (IR) group that received a combination of TKM treatments and CR. This study was approved by the Institutional Review Board (IRB) of the Pusan National University Hospital (H1404-022-017) and was registered on clinicaltrials.gov (NCT02223741).

The participants were enrolled from two university-affiliated hospitals, namely, a TKM hospital, and 3 TKM clinics. Once the guardians agreed for their child to participate in the study, they received detailed written and verbal information. When the guardians confirmed voluntary registration, they were asked to submit written consent. During this process, the guardians were allowed an adequate period to ask questions; the principles of the Declaration of Helsinki were followed at all times. We ensured that they could freely decide whether they wanted to participate in this study, and were certain that this would not affect their clinical care.

\section{Issue of interest}

This study aimed to determine the real-world characteristics of TKM usage among children with $\mathrm{CP}$ and to compare the effectiveness of $\mathrm{CR}$ and IR. Therefore, the participants underwent 
treatment as per the standard protocol, and were subsequently allocated to the $\mathrm{CR}$ or IR group based on the treatment received.

The included participants received treatments for CP, including $\mathrm{CR}$ and TKM treatments (acupuncture and/or herbal medication) according to their doctors' clinical care preferences. Due to ethical issues and study feasibility, the type and intensity of RTs and other treatments were not controlled. The participants underwent optimal treatments as in real-world settings; there was no particular intended treatment. The participants could freely start, cease, or change any conventional or TKM treatments.

\section{Participants}

Patients with a diagnosis of $\mathrm{CP}$ and aged between 6-78 months were included. Patients who had undergone orthopedic surgery due to $\mathrm{CP}$, had congenital muscular disease, hereditary disease, or progressive central nervous system diseases, and those who had severe diseases (i.e., cancer, severe heart disease, or severe infectious disease) were excluded.

\section{Variables}

To evaluate clinical effectiveness, the Gross Motor Function Measure-66 (GMFM-66), Gross Motor Function Classification System (GMFCS), and Pediatric Evaluation of Disability Inventory (PEDI) were evaluated. The primary outcome was GMFM-66; the secondary outcomes were the GMFCS, PEDI, and the number of other health problems. Adverse events (AEs) were recorded at every visit to evaluate the safety of CR and IR. Baseline information including age, height, weight and sex, type of birth, type of $\mathrm{CP}$, and general health conditions including disabilities, other health problems, and conventional treatments used were evaluated.

The types and frequency of TKM therapies used by patients in the IR group were investigated. The number of times of acupuncture use and the number of days of herbal medication were recorded. In addition, the frequency of RT was observed to understand the relationship between TKM therapies and conventional treatments.

\section{Data sources and measurements}

\section{1) Participant survey}

The guardians were asked to complete survey questionnaires on age, sex, and type of birth at baseline. Accompanying disabilities, other health problems, and current/previous received treatments were recorded at baseline (T1), 26 weeks after baseline (T2), and 52 weeks after baseline (T3). 'Accompanying disabilities' included cognitive impairment, seizures, dysphagia, deficiencies in vision, hearing, or language, and musculoskeletal deformation. Other health problems included various health problems not directly related to CP. Treatment-related questions included age at treatment start, weekly RT frequency, experience of botulinum toxin, present use of an assistive device, oral medication, or dietary supplements, and use of TKM treatments. RT included PT, OT, $\mathrm{ST}$, and other rehabilitation therapies directed by the medical doctor. TKM treatments included acupuncture and herbal medications supplied by a registered doctor of TKM.

2) Clinical evaluation 
A pediatric physical therapist with $>5$ years of clinical experience in pediatric RT performed the clinical evaluation. The investigator examined the CP type and GMFCS level at T1; the height, weight, GMFM-66, and PEDI at T1, T2, and T3 were also measured. The investigator visited all the study sites to evaluate all participants.

\section{Study size}

This study sought to enrol 300 participants for initiation (8 subgroups [ $\mathrm{n}=37$, each]; 2 subgroups for each treatment, as well as for GMFCS and age). However, only 182 participants were finally included due to the relatively lower-than-expected recruitment rate and the between-group differences shown by the interim analysis. Therefore, we decided to enrol the 'minimum' number of participants required for meaningful observation.

\section{Statistical analysis}

Continuous and categorical data are presented as means \pm standard deviation and frequencies (percentages), respectively. Between-group differences in continuous and categorical data were assessed using the Wilcoxon rank-sum and Chi-square test/Fisher's exact tests, respectively. Subgroup analysis was performed based on the GMFCS level and age. Participants who did not undergo clinical evaluation were excluded from the analysis. All statistical analyses were two-tailed tests, with a significance level of 0.05 and power of 0.8. All statistical analyses were performed using Strategic Applications Software (SAS, version 9.4; SAS Institute Inc., Cary, NC, USA).

\section{Results}

\section{Participants}

A total of 207 participants provided written informed consent; however, 20 participants withdrew before the baseline survey. During the screening phase, 187 participants answered the baseline survey while 5 withdrew; consequently, 182 participants completed the initial clinical evaluation (T1). At 26 weeks after registration (T2), 39 participants withdrew, with 143 participants completing the second clinical evaluation. At 52 weeks after registration (T3), 10 participants withdrew; thus, 133 participants completed the third clinical evaluation. Before initiating the analysis, 7 participants were excluded for either lacking a CP diagnosis (i.e., they were initially diagnosed with $\mathrm{CP}$ at baseline, with further examination leading to the diagnosis of other diseases, including genetic diseases) or meeting the exclusion criteria. Finally, 126 participants (91, CR group; 35, IR group) were included in the analysis (Figure 1).

\section{Baseline information}

There were no significant differences in age, sex, height, and weight between the IR and CR groups. The IR group had significantly fewer children with spastic CP $(61.9 \%$, IR; 87.9\%, CR; $\mathrm{p}=0.001)$, fewer twin children $(8.3 \%$, IR; 27.5, $\mathrm{CR} ; \mathrm{p}=0.022)$, more 'other health problems' (1.2, IR; 0.6, CR; $\mathrm{p}=0.050)$, and less experience with botulinum toxin treatment $(8.6 \%$, IR; $31.9 \%$, $\mathrm{CR} ; \mathrm{p}=0.007)$. There was no between-group difference in the weekly frequency of RT, use of oral medication and dietary supplements, 


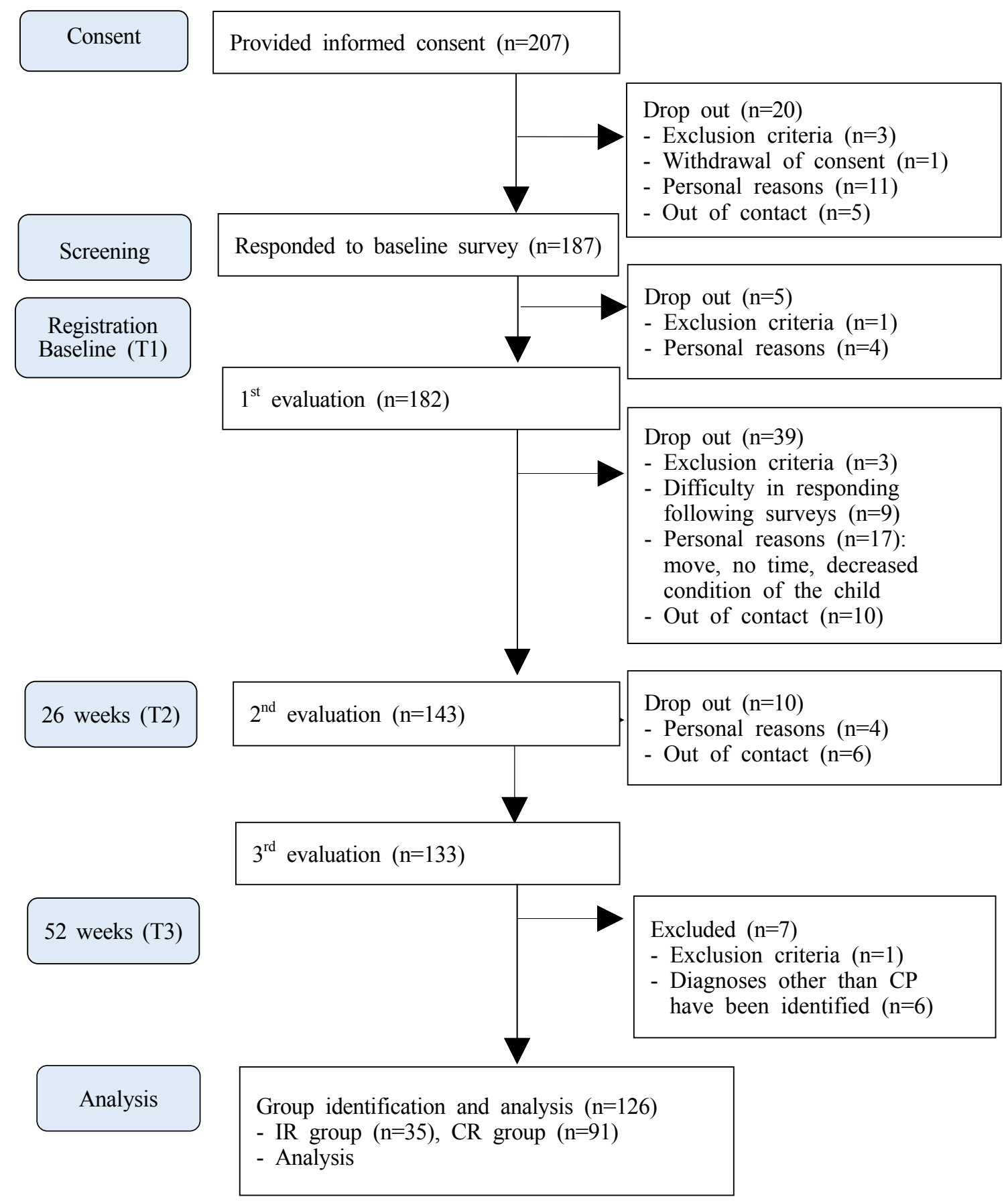

$\mathrm{CR}$, conventional rehabilitation; IR, integrated rehabilitation

Fig. 1. Study flow chart. 
GMFM-66 and PEDI scores, and the distribution of GMFCS levels (Table 1).

\section{Clinical effectiveness and safety}

We primarily focused on the changes between $\mathrm{T} 1$ and $\mathrm{T} 3$ in the analysis and interpretation.

The CR group comprised children who only received CR over the 52-week study period $(\mathrm{n}=$ 91). However, the IR group had children who received more than the specified TKM treatments, i.e., herbal medications over 30 days or acupuncture treatments over 12 sessions for 6 months in addition to CR $(\mathrm{n}=35)$. Consequently, the IR group included: 1) 19 children who received IR for 52 weeks (IR + IR); 2) 11 children who received IR and CR for the first and last 26 weeks, respectively (IR $+\mathrm{CR}$ ); and 3) 5 children who received CR and IR for the first and

Table 1. Baseline information

\begin{tabular}{|c|c|c|c|c|c|}
\hline Variables & & & $\begin{array}{l}\text { CR group } \\
(\mathrm{n}=91)\end{array}$ & $\begin{array}{l}\text { IR group } \\
(\mathrm{n}=35)\end{array}$ & $\mathrm{p}$ value \\
\hline \multirow{4}{*}{$\begin{array}{l}\text { Demographic } \\
\text { characteristics }\end{array}$} & \multicolumn{2}{|c|}{ Age: $\operatorname{mos}(\mathrm{Mean} \pm \mathrm{SD})$} & $34.8 \pm 18.3$ & $30.7 \pm 18.2$ & $0.237 \mathrm{a}$ \\
\hline & \multicolumn{2}{|c|}{ Height: cm (Mean \pm SD) } & $89.2 \pm 11$ & $86.5 \pm 11.9$ & $0.161 \mathrm{a}$ \\
\hline & \multicolumn{2}{|c|}{ Weight: kg (Mean \pm SD) } & $12.5 \pm 3.5$ & $11.6 \pm 3.3$ & $0.095 \mathrm{a}$ \\
\hline & \multicolumn{2}{|c|}{ Sex: male (Cases $(\%))$} & $57(62.6 \%)$ & $24(68.6 \%)$ & $0.534 b$ \\
\hline \multirow[t]{3}{*}{ Type of Birth } & \multicolumn{2}{|c|}{ Artificial insemination (Cases (\%)) } & $11(12.1 \%)$ & $3(8.6 \%)$ & $0.756 \mathrm{c}$ \\
\hline & \multicolumn{2}{|c|}{ Premature birth (Cases (\%)) } & $63(69.2 \%)$ & $22(62.9 \%)$ & $0.494 b$ \\
\hline & \multicolumn{2}{|c|}{ Twins (Cases $(\%)$ ) } & $25(27.5 \%)$ & $3(8.6 \%)$ & $0.022 b^{*}$ \\
\hline \multirow{4}{*}{$\begin{array}{l}\text { Present } \\
\text { condition }\end{array}$} & \multicolumn{2}{|c|}{ Type of CP: spastic type (Cases (\%)) } & $80(87.9 \%)$ & $22(62.9 \%)$ & $0.001 b^{*}$ \\
\hline & \multicolumn{2}{|c|}{ children with accompanying disabilities (Cases (\%)) } & $62(68.1 \%)$ & $26(74.3 \%)$ & $0.500 \mathrm{~b}$ \\
\hline & \multicolumn{2}{|c|}{ children with other health problems (Cases (\%)) } & $37(42.9 \%)$ & $19(54.3 \%)$ & $0.168 b$ \\
\hline & \multicolumn{2}{|c|}{ No. of other health problems (Mean (SD)) } & $0.6(0.9 \%)$ & $1.2(1.5 \%)$ & $0.050 \mathrm{a}$ \\
\hline \multirow[t]{6}{*}{ Treatments } & \multicolumn{2}{|c|}{ Treatment beginning age: $\operatorname{mos}($ Mean $\pm \mathrm{SD})$} & $8.9 \pm 8.6$ & $11.3 \pm 9.8$ & $0.091 \mathrm{a}$ \\
\hline & \multicolumn{2}{|c|}{ RT times per week $($ Mean \pm SD) } & $12.0 \pm 8.2$ & $11.0 \pm 7.8$ & $0.588 \mathrm{a}$ \\
\hline & \multicolumn{2}{|c|}{ Experience of botulinum toxin (Cases (\%)) } & $29(31.9 \%)$ & $3(8.6 \%)$ & $0.007 \mathrm{~b} *$ \\
\hline & \multicolumn{2}{|c|}{ Presently using assist device (Cases (\%)) } & $59(64.8 \%)$ & $18(51.4 \%)$ & $0.167 b$ \\
\hline & \multicolumn{2}{|c|}{ Presently taking oral medication (Cases (\%)) } & $27(29.7 \%)$ & $8(22.9 \%)$ & $0.444 b$ \\
\hline & \multicolumn{2}{|c|}{ Presently using dietary supplements (Cases (\%)) } & $59(64.8 \%)$ & $22(62.9 \%)$ & $0.836 \mathrm{~b}$ \\
\hline \multirow{9}{*}{$\begin{array}{l}\text { Clinical } \\
\text { Evaluation }\end{array}$} & \multicolumn{2}{|c|}{ GMFM-66 (Mean \pm SD) } & $46.5 \pm 19.6$ & $43.4 \pm 19.1$ & $0.449 \mathrm{a}$ \\
\hline & \multirow{5}{*}{$\begin{array}{l}\text { GMFCS } \\
(\text { Cases }(\%))\end{array}$} & Level 1 & $39(42.9 \%)$ & $11(31.4 \%)$ & $0.678 b$ \\
\hline & & Level 2 & $6(6.6 \%)$ & $4(11.4 \%)$ & \\
\hline & & Level 3 & $12(13.2 \%)$ & $6(17.1 \%)$ & \\
\hline & & Level 4 & $16(17.6 \%)$ & $8(22.9 \%)$ & \\
\hline & & Level 5 & $18(19.8 \%)$ & $6(17.1 \%)$ & \\
\hline & \multirow{3}{*}{$\begin{array}{l}\text { PEDI } \\
(\text { Mean } \pm \text { SD) }\end{array}$} & Self-care & $22.1 \pm 17.1$ & $18.1 \pm 14.6$ & $0.335 \mathrm{a}$ \\
\hline & & Mobility & $21.5 \pm 17.7$ & $18.1 \pm 18.7$ & $0.270 \mathrm{a}$ \\
\hline & & Social-function & $23.1 \pm 17.1$ & $17.7 \pm 14.4$ & $0.148 \mathrm{a}$ \\
\hline
\end{tabular}

CR, conventional rehabilitation; IR, integrated rehabilitation; CP, cerebral palsy; GMFM-66, gross motor function measure-66; GMFCS, gross motor function classification system; PEDI, pediatric evaluation of disability inventory; a, Wilcoxon rank sum test; b, Chi-square test; c, Fisher's exact test; ${ }^{*}$, statistically significant $(p<0.05)$ 
last 26 weeks, respectively (CR + IR) (Figure 1).

The changes between $\mathrm{T} 1$ and $\mathrm{T} 2$ were referentially examined (96, CR group; 30, IR group).

\section{1) Changes in clinical outcomes}

The improvement in GMFM-66 was significantly greater in the IR group $(6.4 \pm 6.1)$ than in the CR group $(4.6 \pm 5.8)(\mathrm{p}=0.048)$. The reduction in the number of other health problems was significantly greater in the IR group $(-0.7 \pm 1.1$ and $-0.2 \pm 0.7$ in the IR and CR groups, respectively $[p=0.012]$ ). There was no between -group difference in the PEDI scores, total scores, and item-specific scores (Table 2).

Changes between $\mathrm{T} 1$ and $\mathrm{T} 2$ showed similar tendencies. In particular, there was an increase in the GMFM-66 score by $4.6 \pm 5.0$ and $2.3 \pm 3.6$ in the IR and CR groups $(\mathrm{p}=0.004)$, respectively, while there was a decrease in the number of other health problems by $-0.7 \pm 1.1$ and $-0.2 \pm 0.7$ in the IR and CR groups $(\mathrm{p}=0.012)$, respectively.

\section{2) Other analysis}

A subgroup analysis based on the GMFCS level revealed that the between-group difference was largest for GMFCS level 1 (improvement by $6.3 \pm 3.7$ and $3.5 \pm 3.1$ in the IR [n=11] and CR [ $\mathrm{n}=39]$ groups, respectively, $[\mathrm{p}=0.0324]$ ). The IR group showed non-significantly greater improvements in the GMFCS levels 2, 3, and 5 than those in the CR group (Supplementary File $1)$.

For age-based subgroup analysis, the participants were classified into three groups: age $<24$ months, 24 months $\leq$ age $<48$ months, and 48 months $\leq$ age. None of the subgroups showed significant between-group differences in the

Table 2. The clinical evaluation and use of treatments over the study period

\begin{tabular}{|c|c|c|c|c|}
\hline \multicolumn{2}{|l|}{ Variables } & $\begin{array}{c}\text { CR group } \\
(\mathrm{n}=91)\end{array}$ & $\begin{array}{l}\text { IR group } \\
(\mathrm{n}=35)\end{array}$ & $\mathrm{p}$ value \\
\hline \multicolumn{2}{|l|}{ Height: $\mathrm{cm}^{\S}($ Mean \pm SD $)$} & $7.2 \pm 3.9$ & $7.5 \pm 4.0$ & $0.896 \mathrm{a}$ \\
\hline \multicolumn{2}{|l|}{ Weight: $\mathrm{kg}^{\S}($ Mean $\pm \mathrm{SD})$} & $2.0 \pm 1.4$ & $1.8 \pm 1.1$ & $0.609 a$ \\
\hline \multicolumn{2}{|l|}{ GMFM- $66^{\S}($ Mean \pm SD) } & $4.6 \pm 5.8$ & $6.4 \pm 6.1$ & $0.048 \mathrm{a}^{*}$ \\
\hline \multirow[t]{4}{*}{$\mathrm{PEDI}^{\S}(\mathrm{Mean} \pm \mathrm{SD})$} & Self-care & $7.1 \pm 6.0$ & $5.2 \pm 4.8$ & $0.168 \mathrm{a}$ \\
\hline & Mobility & $6.8 \pm 7.7$ & $7.8 \pm 9.3$ & $0.794 a$ \\
\hline & Social-function & $6.9 \pm 6.6$ & $6.7 \pm 4.9$ & $0.840 \mathrm{a}$ \\
\hline & Total score & $20.8 \pm 17.6$ & $19.6 \pm 16.2$ & $0.836 \mathrm{a}$ \\
\hline \multicolumn{2}{|c|}{ No. of other health problems ${ }^{\S}($ Mean \pm SD) } & $-0.2 \pm 0.7$ & $-0.7 \pm 1.1$ & $0.012 \mathrm{a}^{*}$ \\
\hline \multicolumn{2}{|c|}{ Frequency of RT (times/week) ${ }^{\dagger}($ Mean \pm SD) } & $12.0 \pm 9.9$ & $10.9 \pm 6.6$ & 0.7362 \\
\hline \multicolumn{2}{|l|}{ Use of TKM in the IR group } & & Mean \pm SD & {$[\min , \max ]$} \\
\hline \multirow[t]{2}{*}{ Use of acupuncture (times) $^{\dagger}$} & Overall $(\mathrm{n}=35)$ & & $45.3 \pm 54.4$ & {$[0,231]$} \\
\hline & Acupuncture users ( $\mathrm{n}=27)$ & & $60.0 \pm 54.2$ & {$[8,231]$} \\
\hline \multirow[t]{2}{*}{ Use of herbal medication (days) $^{\dagger}$} & Overall $(n=35)$ & & $120.5 \pm 126.7$ & {$[0,364]$} \\
\hline & Herbal medication users $(n=28)$ & & $152.0 \pm 122.6$ & {$[14,364]$} \\
\hline
\end{tabular}

\&, differences between $\mathrm{T} 1$ and $\mathrm{T} 3(\mathrm{~T} 3-\mathrm{T} 1) ;{ }^{\dagger}$, average value of 1 -year observation; CR, conventional rehabilitation; IR, integrated rehabilitation; GMFM-66, gross motor function measure-66; PEDI, paediatric evaluation of disability inventory; a, Wilcoxon rank sum test; NA, not-applicable; *, statistically significant $(p<0.05)$ 
GMFM-66 score. However, the age $<24$ months group showed the largest reduction in the number of other health problems $(-0.9 \pm 1.3$ and $-0.2 \pm$ 0.8 in the IR and CR groups, respectively, $[\mathrm{p}=$ 0.029]) (Supplementary File 2).

There were no significant differences between the 'IR+IR ( $=19)$ ' and 'CR+IR or IR+CR (n $=16)$ ' groups.

\section{3) Adverse events}

All AEs, including AEs not directly related to the $\mathrm{CR}$ or IR, were recorded. Analysis and interpretation of AEs were performed for 133 participants who adhered to $\mathrm{T} 3$ to consider exclusions or withdrawals caused by AEs.

The AE occurrence per participant was $5.5 \pm$ 3.8 and $5.9 \pm 4.0$ in the IR and CR groups, respectively. There were 764 AEs, with respiratory infections (79.8\%) being the most frequent, followed by dyspepsia/enteritis $(6.8 \%)$. There was no between-group difference in the distribution of the AE types. Skin rashes associated with TKM treatment were found in one case; the rash was relieved by discontinuing the herbal medication. No serious adverse events were observed.

\section{4) Comparison between 'the drop-out' and 'the complete'}

Among the 182 registered children, 133 and 49 children adhered (completed) and withdrew (dropped-out) from the final evaluation, respectively. Comparison of the two groups (completed and dropped-out) to determine whether any factors influenced drop-out revealed no between-group differences in age, sex, type of birth, type of CP, type of treatment, baseline GMFCS, GMFM-66, and PEDI.

\section{Characteristics of TKM usage}

No intended treatments were set in this study; instead, the participants were allowed freedom of choice of RTs or TKM treatments. Moreover, the contents and changes of treatments were recorded.

During the entire study period, there was no significant between-group differences in the weekly frequency of RTs $(10.9 \pm 6.6$ and $12.0 \pm$ 9.9 times per week in the IR and CR groups, respectively, $[\mathrm{p}=0.7362])$. In both groups, PT was the most frequently used RT form, followed by OT and ST.

During the study period, the IR group received an average of $45.3 \pm 54.4$ acupuncture treatments and $120 \pm 126.7$ days of herbal medication. For participants who received acupuncture treatments $(\mathrm{n}=27)$ or herbal medication $(\mathrm{n}=28)$, the average, minimum, and maximum number of acupuncture treatments were $60.0,8$, and 231 times; the corresponding values for herbal medication were 152.0, 14, and 364 days (Table 2).

\section{Discussion}

In this study, the IR group showed greater improvement than the $\mathrm{CR}$ group in terms of the GMFM-66 score and reduction in the number of other health problems; and the RT frequency was not influenced by TKM use; the approximate mean frequency and duration of use was 60 times for acupuncture and 150 days for herbal medication in patients using those treatments during one year. 
Murphy et al have highlighted that the lesion of $\mathrm{CP}$ is not progressive, but childhood $\mathrm{CP}$ is not a clinically static condition. The condition of children can be widely affected by the children's muscular-skeletal or organic changes while they grow up ${ }^{14)}$. In addition, children with $\mathrm{CP}$ have complex problems in physical, psychological, communicative, and social aspects so that multidisciplinary approach is needed ${ }^{15)}$. In TKM, the CP symptoms are recorded as stiffness, limpness, and cognitive retardation. ${ }^{16)}$ Previous studies have reported that acupuncture or herbal medicine combined with conventional treatment improves motor, mental, and verbal function, as well as daily life activities in children with $\mathrm{CP}$. However, these studies had small sample sizes and short follow-up periods; further studies are therefore needed. ${ }^{17,18)}$ Acupuncture and herbal medicine are the major TKM modalities, and are often used concomitantly. Since CP requires a long treatment period, treatments can be applied in various ways; both acupuncture and herbal medicine can be used, only one can be used, and both can be stopped and restarted. Therefore, individuals who used only one or both treatments, namely, acupuncture and herbal medicine were classified into the $\mathrm{CR}$ group. Additionally, we attempted to reflect the real-world settings by allowing the participants to freely make decisions regarding TKM use. This was also performed to adhere to research ethics and improve the feasibility, given the long follow-up period.

Regarding the characteristics of TKM users, the IR group had a greater number of children with non-spastic $\mathrm{CP}$ than the $\mathrm{CR}$ group, and consequently a lower experience of botulinum toxin treatments. A previous study reported that children with non-spastic CP had a higher rate of TKM use than children with spastic CP. ${ }^{19)}$ We previously observed that children with non-spastic CP tended to use TKM more than those with spastic CP. ${ }^{13)}$ The present findings are consistent with these previous findings. This suggests that TKM is more accessible to patients with uncommon atonic, ataxic, or mixed $\mathrm{CP}$ than to those with spastic CP. There were no between-group differences in the mean age and distribution of GMFCS levels.

The therapeutic effects of IR and CR were assessed based on the GMFM-66, GMFCS, and PEDI scores, as well as other health problems over the 1-year observation period.

The IR group showed greater improvement in the GMFM-66 scores when compared with the CR group (6.4, IR group; 4.6, CR group). Due to ethical issues and study feasibility, the type and intensity of RTs and other treatments were not controlled; however, there was no between-group difference at baseline and during the 1 year. Additionally, the RT type showed a similar pattern in PT, OT, and ST. The difference in RT intensity did not appear to affect the between -group difference in the improvement of the GMFM-66 score, since the weekly frequency of RT in the IR group was rather small. Moreover, there was no statistical significance.

A subgroup analysis based on the GMFCS level was performed since the prognosis of the GMFM-66 score is affected by the GMFCS level. There was a greater improvement from baseline in levels 1 and 2; this finding is similar to those of previous reports. ${ }^{20,21)}$ The between-group 
differences in changes were the largest in level 1 (6.2, IR group; 3.5, CR group; $\mathrm{p}=0.032$ ) (Supplementary File 1). The baseline GMFM-66 scores of children with GMFCS level 1 in the IR and $\mathrm{CR}$ groups were $63.8 \pm 6.2$ and $64.9 \pm 5.8$ $(\mathrm{p}=0.704)$, respectively, with corresponding mean ages of $36.5 \pm 15.9$ years and $39.0 \pm 18.5$ years $(\mathrm{p}=0.825)$. This indicates that children with milder symptoms (GMFCS level 1) are generally more prone to improvement and responding to TKM. However, these findings should be carefully interpreted, and there is a need for further research given our small sample size, which limited the statistical analysis. Furthermore, the CP type is known to affect its prognosis. Given that the IR group had more patients with non-spastic $\mathrm{CP}$ than the general distribution, ${ }^{22)}$ we performed a subgroup analysis using children with spastic CP. Compared with the CR group, the IR group showed a non -significantly greater improvement (comparison between T1 and T3: 6.3 \pm 7.2 in the IR group $[n=22]$ and $4.5 \pm 5.9$ in the CR group $[\mathrm{n}=80], \mathrm{p}=0.282$; comparison between T1 and T2: $4.4 \pm 5.8$ in the IR group [n $=18]$ and $2.5 \pm 3.7$ in the CR group [n $=84]$, $\mathrm{p}=0.061$ ). Although the statistical analysis was limited owing to the small number of children with spastic CP in the IR group, our findings indicate that IR may be helpful for children, regardless of the $\mathrm{CP}$ type.

Compared with the CR group, the IR group showed greater improvement in 'other health problems'. In South Korea, TKM has been used to improve the general health status in children with disabilities ${ }^{23)}$; furthermore, it is more commonly used among children with neuropsychiatric diseases. ${ }^{24)}$ Moreover, in this study, the IR group had more children with other health problems than the CR group $(p=0.0497)$. Children aged $<$ 24 months showed the greatest reduction in other health problems; this suggests that TKM could be more helpful for younger children with frequent and varying health problems. Generally, children with any GMFCS level show a plateau in the GMFM-66 score after 6-7 years; furthermore, the treatment goal is to prevent any further decline in the score. ${ }^{20,21)}$ In the same context, early RT is effective due to neural plasticity ${ }^{25,26}$ with an emphasis on more treatments at a young age. ${ }^{27)}$ Therefore, IR is more effective when applied at a younger age.

Regarding AEs, skin rash was identified in one case; this may have been caused by the herbal medication. The skin rash naturally cleared after discontinuing treatment with the herbal medication. Therefore, acupuncture and herbal medication can be considered as safe treatments; however, future studies should perform continuous observation.

This study has several limitations. First, the CP type could not be evenly set at baseline and also influenced the choice of treatment content. Second, the sample size was insufficient for adequate subgroup or stratification analysis, which could have allowed more detailed evaluation and judgment. Finally, since the guardians often stopped and restarted the TKM treatments; the TKM intensity was therefore relatively low compared with the generally recommended intensity for achieving a therapeutic effect. This low intensity was insufficient for establishing the efficacy or safety of TKM, and resulted from applying the real-world usage pattern. Therefore, 
future randomized control trials should implement a higher TKM intensity to elucidate the efficacy and safety of TKM. Nonetheless, the current study presents meaningful data, since it reports the results of 1-year observation within clinical settings.

TKM treatments may provide additional benefits in terms of improvement of the GMFM-66 score, especially among children with mild symptoms (GMFCS level 1), and reduction in other health problems. The use of TKM does not affect the use of RT.

\section{List of Abbreviation}

CP, cerebral palsy; TKM, traditional Korean medicine; RT, rehabilitation therapy; $\mathrm{CR}$, conventional rehabilitation; IR, integrated rehabilitation; IRB, institutional review board; GMFM-66, Gross Motor Function measure-66; GMFCS, Gross Motor Function Classification System; PEDI, pediatric evaluation of disability inventory; AE, Adverse event; PT, physical therapy; OT, occupational therapy; ST, speech therapy

\section{Acknowledgemens}

This study was supported by the Convergence of Conventional Medicine and Traditional Korean Medicine R\&D program funded by the Ministry of Health \& Welfare through the Korea Health Industry Development Institute (KHIDI); grant number, HI14C0704.

\section{Ethics Approval and Consent to Participate}

This study was approved by the IRB of Pusan National University Hospital (H1404-022-017). This study was conducted in compliance with the Declaration of Helsinki, the Ethical Guidelines for Korea Good Clinical Practice, and relevant laws and regulations. All the participants provided written consent for participation.

\section{Consent for Publication}

Not applicable

\section{Availability of Data and Materials}

The datasets used and/or analyzed during the current study are available from the corresponding author upon reasonable request.

\section{Authors Contributions}

YY conceived the research question, designed the study, and bore full responsibility for the manuscript and study. HL interpreted the data and wrote the draft. JH conducted the statistical analysis and interpreted the statistics. SY interpreted TKM use and pediatric data. YS and SK interpreted the pediatric rehabilitation data. All authors participated in the critical review of the draft and approved the final version of the manuscript.

\section{Conflict of Interest}

The authors of this work have nothing to 
disclose.

\section{References}

1. Miller, F. (2006). Cerebral Palsy : A Complete Guide for Caregiving. Johns Hopkins University Press.

2. Hurvitz, E. A., Leonard, C., Ayyangar, R., \& Nelson, V. S. (2003). Complementary and alternative medicine use in families of children with cerebral palsy. Developmental Medicine \& Child Neurology, 45(6), 364-370. doi:10.1017/S0012162203000707

3. Wray, J., Edwards, V., Wyatt, K., Maddick, A., Logan, S., \& Franck, L. (2014). Parents' attitudes toward the use of complementary therapy by their children with moderate or severe cerebral palsy. Journal of Alternative and Complementary Medicine, 20(2), 130-135. https://doi.org/10.1089/acm.2012.0973

4. McCann, L., \& Newell, S. (2006). Survey of paediatric complementary and alternative medicine use in health and chronic illness. Archives of Diseases in Childhood, 91(2), 173-174. https://doi.org/10.1136/adc.2004.052514

5. Cheshire, A., Powell, L., \& Barlow, J. (2007). Use of complementary and alternative medicine for children with brain injury in the United Kingdom. The Journal of Alternative and Complementary Medicine, 13(7), 703-704. https://doi.org/10.1089/acm.2007.7158

6. Jeong, M.-J., Lim, J.-H., HwangBo, M., Kim, K.-B., \& Yun, Y.-J. (2012). A study on the utilization of Korean medicine \& other parallel treatments for neurological disease children \& adolescents treated with western medicine. The Journal of Pediatrics of Korean Medicine, 26(2), 72-84. https://doi.org/10.7778/ JPKM.2012.26.2.072

7. Park, B., Park, Y., Yu, S., Hur, Y., Kim, S., \& Yun, Y.-J. (2016). Study on the Current Utilization and the Reason of Ceasing Korean Medicine Treatment among Children with Cerebral Palsy. Journal of Society of Preventive Korean Medicine 20(1), 89-97.

8. National health service. (2021). Cerebral palsy treatment. Retrieved July 27 from https://www.nhs.uk/conditions/cerebral-palsy/t reatment/

9. Mayo Clinic. (2021). Diagnosis and treatment, Cerebral palsy Retrieved July 27 from https://www.mayoclinic.org/diseases-condition s/cerebral-palsy/diagnosis-treatment/drc-20354 005

10. Liao C, Z. J. (2011). Meta-analysis on acupuncture in treatment of cerebral palsy. Chinese General Practice, 14, 1229-1231.

11. Jing Z, Z. L., \& Shao XN. (2013). Meta analysis of acupuncture treatment for children with cerebral palsy. Guiding J Traditional Chinese Medicine and Pharmacy 19, 62-65.

12. Zhang, Y., Liu, J., Wang, J., \& He, Q. (2010). Traditional Chinese Medicine for treatment of cerebral palsy in children: a systematic review of randomized clinical trials. J Altern Complement Med, 16(4), 375-395. https://doi.org/ 10.1089/acm.2009.0609

13. Lee, H.-Y., Yun, Y.-J., Yu, S.-A., Park, Y.-H., Park, B.-W., Kim, B.-Y., \& Hwang, M.-S. (2018). A cross-sectional survey of clinical factors that influence the use of traditional Korean medicine among children with 
cerebral palsy. Integrative Medicine Research. https://doi.org/https://doi.org/10.1016/j.imr.20 18.07.001

14. Murphy, N., \& Such-Neibar, T. (2003). Cerebral palsy diagnosis and management: the state of the art. Current problems in pediatric and adolescent health care, 33(5), 146-169. https://doi.org/10.1016/S1538-5442(03) 00002-6

15. Becher, J. G. (2002). Pediatric Rehabilitation in Children with Cerebral Palsy: General Management, Classification of Motor Disorders. JPO: Journal of Prosthetics and Orthotics, 14(4), 143-149. https://journals.lww. com/jpojournal/Fulltext/2002/12000/Pediatric_ Rehabilitation_in_Children_with_Cerebral.4.a spx

16. Park, J. H., \& Paeck, E. K. (2010). Disease related to the five retardation, five limpness, five stiffness. Korean J. Oriental physiology \& pathology, 24(2), 197-205.

17. L.-X., Zhang, M.-M., Zhang, Y., \& He, J. (2018). Acupuncture for cerebral palsy: A meta-analysis of randomized controlled trials. Neural regeneration research, 13(6), 1107-1117. https://doi.org/10.4103/1673-5374.233455

18. Zhang, Y., Liu, J., Wang, J., \& He, Q. (2010). Traditional Chinese Medicine for treatment of cerebral palsy in children: a systematic review of randomized clinical trials. J Altern Complement Med, 16(4), 375-395. https://doi.org/ 10.1089/acm.2009.0609

19. Hong, J. S. (2004). A study on health care utilization of children with cerebral palsy. Master's Thesis, Seoul National University, Graduate School of Public Health.
http://www.riss.kr/link?id=T9588524

20. Rosenbaum, P. L., Walter, S. D., Hanna, S. E., Palisano, R. J., Russell, D. J., \& Raina, P. et al. (2002). Prognosis for gross motor function in cerebral palsy: Creation of motor development curves. JAMA, 288(11), 1357-1363. https://doi.org/10.1001/jama.288.11.1357

21. Hanna, S. E., Rosenbaum, P. L., Bartlett, D. J., Palisano, R. J., Walter, S. D., Avery, L., \& Russell, D. J. (2009). Stability and decline in gross motor function among children and youth with cerebral palsy aged 2 to 21 years. Developmental Medicine \& Child Neurology, 51(4), 295-302. https://doi.org/10.1111/j.1469 -8749.2008.03196.x

22. Russell DJ, R. P., Avery LM, Lane M. . (2012). Gross motor function measure (GMFM-66 GMFM-88) user's manual. (Vol. 2ed). Mac Keith Press.

23. Jung, S. K., Yu, S., \& Lee, S. Y. (2012). The correlation study between developmental disability and weak symptoms. Journal of Pediatrics of Korean Medicine, 26(2), 25-34.

24. Jeong, M. J., Lee, H. Y., Lim, J. H., \& Yun, Y. J. (2016). Current utilization and influencing factors of complementary and alternative medicine among children with neuropsychiatric disease: a cross-sectional survey in Korea. BMC Complement Altern Med, 16(1), 1-8. https://doi.org/10.1186/s12906-016-1066-4

25. Korean Society of pediatric rehabilitation and developmental medicine. (2013). Pediatric Rehabilitation (Vol. 2). Koonja.

26. Holt, R. L., \& Mikati, M. A. (2011). Care for child development: basic science rationale and effects of interventions. Pediatr Neurol, 
(510) Journal of Korean Medicine 2021;42(4)

44(4), 239-253. https://doi.org/10.1016/j.pedi atrneurol.2010.11.009

27. Park, M. S., Kim, S. J., Chung, C. Y., Kwon, D. G., Choi, I. H., \& Lee, K. M. (2011). Prevalence and lifetime healthcare cost of cerebral palsy in South Korea. Health Policy, 100(2-3), 234-238. https://doi.org/10.1016/j.healthpol. 2010.09.010

\section{ORCID}

Hye-Yoon Lee https://orcid.org/0000-0002-9486-1703

Young-Ju Yun https://orcid.org/0000-0002-4598-2322 Yong-Beom Shin https://orcid.org/0000-0001-5026-1696 Soo-Yeon Kim https://orcid.org/0000-0001-5679-0126 Jun-hee Han https://orcid.org/0000-0001-5736-8752 Sun-ae Yu https://orcid.org/0000-0001-6502-743X 
Supplementary File 1. Subgroup analysis based on GMFCS level.

\begin{tabular}{|c|c|c|c|c|c|}
\hline GMFCS level & Variables & & CR group & IR group & $\mathrm{p}$ value \\
\hline \multirow[t]{9}{*}{$1(\mathrm{n}=39: 11)$} & Mean age $^{\dagger}$ & $(\mathrm{Mean} \pm \mathrm{SD})$ & $39.0 \pm 18.5$ & $36.5 \pm 15.9$ & 0.825 \\
\hline & Height: $\mathrm{cm}^{\S}$ & $(\mathrm{Mean} \pm \mathrm{SD})$ & $7.9 \pm 2.8$ & $7.3 \pm 1.0$ & 0.429 \\
\hline & Weight: $\mathrm{kg}^{\S}$ & $(\mathrm{Mean} \pm \mathrm{SD})$ & $2.4 \pm 1.2$ & $2.6 \pm 1.2$ & 0.449 \\
\hline & GMFM- $66^{\S}$ & $(\mathrm{Mean} \pm \mathrm{SD})$ & $3.5 \pm 3.1$ & $6.2 \pm 3.7$ & $0.032^{*}$ \\
\hline & $\mathrm{PEDI}^{\S}$ & Self-care & $8.7 \pm 5.2$ & $7.9 \pm 3.8$ & 0.806 \\
\hline & $(\mathrm{Mean} \pm \mathrm{SD})$ & Mobility & $8.3 \pm 6.5$ & $8.7 \pm 7.6$ & 0.735 \\
\hline & & Social-function & $7.6 \pm 7.0$ & $7.8 \pm 4.4$ & 0.889 \\
\hline & & Total score & $24.6 \pm 15$ & $24.5 \pm 12.7$ & 0.825 \\
\hline & No. of other $\mathrm{h}$ & $\mathrm{ms}^{\S}(\mathrm{Mean} \pm \mathrm{SD})$ & $-0.2 \pm 0.6$ & $-0.3 \pm 0.8$ & 0.688 \\
\hline \multirow[t]{9}{*}{$2(n=6: 4)$} & Mean age $^{\dagger}$ & $($ Mean \pm SD) & $32.8 \pm 16.2$ & $36.5 \pm 23.6$ & 1.000 \\
\hline & Height: $\mathrm{cm}^{\S}$ & $($ Mean \pm SD $)$ & $7.2 \pm 3.2$ & $6.0 \pm 2.0$ & 0.413 \\
\hline & Weight: $\mathrm{kg}^{\S}$ & $(\mathrm{Mean} \pm \mathrm{SD})$ & $3.1 \pm 2.1$ & $2.1 \pm 0.9$ & 0.415 \\
\hline & GMFM- $66^{\S}$ & $(\mathrm{Mean} \pm \mathrm{SD})$ & $7.5 \pm 5.3$ & $8.8 \pm 9.7$ & 0.917 \\
\hline & $\mathrm{PEDI}^{\S}$ & Self-care & $12.0 \pm 8.0$ & $7.3 \pm 6.4$ & 0.415 \\
\hline & $(\mathrm{Mean} \pm \mathrm{SD})$ & Mobility & $15.0 \pm 9.0$ & $16.5 \pm 16.4$ & 1.000 \\
\hline & & Social-function & $12.2 \pm 9.3$ & $11.0 \pm 5.6$ & 0.607 \\
\hline & & Total score & $39.2 \pm 24.4$ & $34.8 \pm 22.6$ & 0.835 \\
\hline & No. of other $\mathrm{h}$ & $\mathrm{ms}^{\S}(\mathrm{Mean} \pm \mathrm{SD})$ & $-0.2 \pm 0.4$ & $-0.5 \pm 1.3$ & 0.726 \\
\hline \multirow[t]{9}{*}{$3(\mathrm{n}=12: 6)$} & Mean age ${ }^{\dagger}$ & $($ Mean \pm SD $)$ & $31.8 \pm 15.2$ & $25.0 \pm 13.6$ & 0.410 \\
\hline & Height: $\mathrm{cm}^{\S}$ & $(\mathrm{Mean} \pm \mathrm{SD})$ & $7.5 \pm 4.8$ & $8.4 \pm 3.1$ & 0.645 \\
\hline & Weight: $\mathrm{kg}^{\S}$ & $($ Mean \pm SD $)$ & $1.6 \pm 0.9$ & $1.3 \pm 1.1$ & 0.677 \\
\hline & GMFM-66 $6^{\S}$ & $(\mathrm{Mean} \pm \mathrm{SD})$ & $5.5 \pm 6.3$ & $8.0 \pm 10.4$ & 0.613 \\
\hline & $\mathrm{PEDI}^{\S}$ & Self-care & $9.9 \pm 5.7$ & $5.0 \pm 3.9$ & 0.118 \\
\hline & $(\mathrm{Mean} \pm \mathrm{SD})$ & Mobility & $7.4 \pm 4.6$ & $8.5 \pm 12.3$ & 0.407 \\
\hline & & Social-function & $9.9 \pm 6.3$ & $6.2 \pm 4.8$ & 0.163 \\
\hline & & Total score & $27.3 \pm 13.3$ & $19.7 \pm 18.5$ & 0.140 \\
\hline & No. of other $\mathrm{h}$ & $\mathrm{ms}^{\S}(\mathrm{Mean} \pm \mathrm{SD})$ & $-0.4 \pm 0.8$ & $-0.3 \pm 1.0$ & 0.869 \\
\hline \multirow[t]{9}{*}{$4(n=16: 8)$} & Mean age ${ }^{\dagger}$ & $($ Mean \pm SD) & $30.8 \pm 20.3$ & $29.0 \pm 24.7$ & 0.762 \\
\hline & Height: $\mathrm{cm}^{\S}$ & $(\mathrm{Mean} \pm \mathrm{SD})$ & $7.9 \pm 4.7$ & $6.8 \pm 5.5$ & 0.628 \\
\hline & Weight: kg ${ }^{\S}$ & $(\mathrm{Mean} \pm \mathrm{SD})$ & $1.7 \pm 0.7$ & $1.7 \pm 0.5$ & 0.976 \\
\hline & GMFM-66 & $(\mathrm{Mean} \pm \mathrm{SD})$ & $8.3 \pm 10.2$ & $6.6 \pm 5.1$ & 0.928 \\
\hline & $\mathrm{PEDI}^{\S}$ & Self-care & $5.0 \pm 5.8$ & $3.1 \pm 5.2$ & 0.585 \\
\hline & $(\mathrm{Mean} \pm \mathrm{SD})$ & Mobility & $6.6 \pm 11.1$ & $6.5 \pm 5.5$ & 0.544 \\
\hline & & Social-function & $5.8 \pm 5.8$ & $5.5 \pm 5.6$ & 0.976 \\
\hline & & Total score & $17.4 \pm 20.6$ & $15.1 \pm 14.8$ & 1.000 \\
\hline & No. of other $\mathrm{h}$ & $\mathrm{ms}^{\S}(\mathrm{Mean} \pm \mathrm{SD})$ & $-0.1 \pm 0.7$ & $-1.6 \pm 1.1$ & $0.004^{*}$ \\
\hline \multirow[t]{9}{*}{$5(\mathrm{n}=18: 6)$} & Mean age $^{\dagger}$ & $($ Mean \pm SD) & $32.1 \pm 18.7$ & $24.3 \pm 13.5$ & 0.451 \\
\hline & Height: $\mathrm{cm}^{\S}$ & $(\mathrm{Mean} \pm \mathrm{SD})$ & $4.9 \pm 5.5$ & $8.8 \pm 6.8$ & 0.217 \\
\hline & Weight: $\mathrm{kg}^{\S}$ & $(\mathrm{Mean} \pm \mathrm{SD})$ & $1.6 \pm 0.5$ & $1.0 \pm 0.4$ & 0.661 \\
\hline & GMFM- $66^{\S}$ & $(\mathrm{Mean} \pm \mathrm{SD})$ & $2.1 \pm 5.1$ & $3.2 \pm 1.9$ & 0.393 \\
\hline & $\mathrm{PEDI}^{\S}$ & Self-care & $1.8 \pm 5.2$ & $1.7 \pm 2.3$ & 0.946 \\
\hline & $(\mathrm{Mean} \pm \mathrm{SD})$ & Mobility & $0.7 \pm 5.5$ & $1.2 \pm 1.7$ & 0.631 \\
\hline & & Social-function & $2.7 \pm 5.6$ & $3.8 \pm 2.9$ & 0.355 \\
\hline & & Total score & $5.2 \pm 14.8$ & $6.7 \pm 5.5$ & 0.766 \\
\hline & No. of other $\mathrm{h}$ & $\mathrm{ms} \S($ Mean \pm SD $)$ & $-0.2 \pm 1.1$ & $-0.5 \pm 1.0$ & 0.398 \\
\hline
\end{tabular}

${ }^{\dagger}$, average age at baseline; ${ }^{\S}$, differences between T1 and T3 (T3-T1); CR, conventional rehabilitation; IR, integrated rehabilitation; GMFM-66, gross motor function measure-66; PEDI, paediatric evaluation of disability inventory; 
Supplementary File 2. Subgroup analysis based on age.

\begin{tabular}{|c|c|c|c|c|c|}
\hline Age & Variables & & CR group $(n=35)$ & IR group $(\mathrm{n}=15)$ & $\mathrm{p}$ value \\
\hline$<24$ & Mean age $^{\dagger}$ & $($ Mean \pm SD) & $16.0 \pm 4.4$ & $15.9 \pm 5.8$ & 0.895 \\
\hline \multirow[t]{8}{*}{$(\operatorname{mos})$} & Height: $\mathrm{cm}^{\S}$ & $(\mathrm{Mean} \pm \mathrm{SD})$ & $8.5 \pm 4.4$ & $8.8 \pm 5.2$ & 0.962 \\
\hline & Weight: $\mathrm{kg}^{\S}$ & $(\mathrm{Mean} \pm \mathrm{SD})$ & $2.1 \pm 1.4$ & $1.8 \pm 0.8$ & 0.649 \\
\hline & GMFM- $66^{\S}$ & $(\mathrm{Mean} \pm \mathrm{SD})$ & $8.5 \pm 7.9$ & $10.0 \pm 7.4$ & 0.397 \\
\hline & $\mathrm{PEDI}^{\S}$ & Self-care & $9.2 \pm 6.7$ & $4.9 \pm 4.8$ & 0.089 \\
\hline & $($ Mean $\pm \mathrm{SD})$ & Mobility & $9.6 \pm 10.3$ & $12.6 \pm 12.2$ & 0.396 \\
\hline & & Social-function & $9.9 \pm 7.0$ & $8.4 \pm 5.7$ & 0.550 \\
\hline & & Total score & $28.6 \pm 21.3$ & $25.9 \pm 20.9$ & 0.624 \\
\hline & \multicolumn{2}{|c|}{ No. of other health problems ${ }^{\S}($ Mean \pm SD $)$} & $-0.2 \pm 0.8$ & $-0.9 \pm 1.3$ & $0.029^{*}$ \\
\hline Age & Variables & & $\mathrm{CR}(\mathrm{n}=37)$ & $\operatorname{IR}(n=12)$ & $\mathrm{p}$ value \\
\hline $24-47$ & Mean age $^{\dagger}$ & $(\mathrm{Mean} \pm \mathrm{SD})$ & $33.5 \pm 7.0$ & $30.6 \pm 6.5$ & 0.175 \\
\hline \multirow[t]{8}{*}{$(\operatorname{mos})$} & Height: $\mathrm{cm}^{\S}$ & $(\mathrm{Mean} \pm \mathrm{SD})$ & $6.5 \pm 3.4$ & $7.3 \pm 2.1$ & 0.685 \\
\hline & Weight: $\mathrm{kg}^{\S}$ & $(\mathrm{Mean} \pm \mathrm{SD})$ & $1.8 \pm 1.1$ & $1.7 \pm 1.2$ & 0.862 \\
\hline & GMFM- $66^{\S}$ & $(\mathrm{Mean} \pm \mathrm{SD})$ & $3.4 \pm 3.0$ & $4.2 \pm 3.2$ & 0.481 \\
\hline & $\mathrm{PEDI}^{\S}$ & Self-care & $7.5 \pm 5.6$ & $5.7 \pm 4.6$ & 0.361 \\
\hline & $(\mathrm{Mean} \pm \mathrm{SD})$ & Mobility & $6.8 \pm 6.1$ & $4.6 \pm 3.5$ & 0.327 \\
\hline & & Social-function & $7.4 \pm 5.7$ & $4.4 \pm 4.1$ & 0.149 \\
\hline & & Total score & $21.8 \pm 14.8$ & $14.7 \pm 10.1$ & 0.094 \\
\hline & \multicolumn{2}{|c|}{ No. of other health problems ${ }^{\S}($ Mean \pm SD $)$} & $-0.2 \pm 0.7$ & $-0.6 \pm 0.8$ & 0.155 \\
\hline Age & Variables & & $\mathrm{CR}(\mathrm{n}=24)$ & $\operatorname{IR}(n=8)$ & $\mathrm{p}$ value \\
\hline$>47$ & Mean age $^{\dagger}$ & $($ Mean \pm SD) & $60.4 \pm 7.9$ & $58.8 \pm 10.5$ & 0.635 \\
\hline \multirow[t]{8}{*}{ (mos) } & Height: $\mathrm{cm}^{\S}$ & $(\mathrm{Mean} \pm \mathrm{SD})$ & $6.6 \pm 3.7$ & $5.4 \pm 2.7$ & 0.401 \\
\hline & Weight: $\mathrm{kg}^{\S}$ & $(\mathrm{Mean} \pm \mathrm{SD})$ & $2.3 \pm 1.7$ & $2.0 \pm 1.4$ & 0.635 \\
\hline & GMFM- $66^{\S}$ & $($ Mean \pm SD $)$ & $1.4 \pm 2.4$ & $2.8 \pm 2.1$ & 0.201 \\
\hline & $\mathrm{PEDI}^{\S}$ & Self-care & $3.8 \pm 4.0$ & $5.0 \pm 5.5$ & 0.712 \\
\hline & $($ Mean $\pm \mathrm{SD})$ & Mobility & $3.4 \pm 3.9$ & $3.5 \pm 4.0$ & 0.664 \\
\hline & & Social-function & $2.4 \pm 5.0$ & $6.9 \pm 2.9$ & $0.025^{*}$ \\
\hline & & Total score & $9.6 \pm 9.0$ & $15.4 \pm 9.2$ & 0.116 \\
\hline & \multicolumn{2}{|c|}{ No. of other health problems ${ }^{\S}($ Mean \pm SD $)$} & $-0.2 \pm 0.7$ & $-0.3 \pm 1.0$ & 0.858 \\
\hline
\end{tabular}

